\title{
Application of Courseware Based on Information Retrieval Technology
}

\author{
http://dx.doi.org/10.3991/ijet.v11i03.5346 \\ Aili Qi ${ }^{1}$, Yunsong Wang ${ }^{2}$, Chengchun Shen ${ }^{1}$ \\ ${ }^{1}$ Guizhou University of Engineering Science, Bijie, China \\ ${ }^{2}$ Guizhou Minzu University, Zunyi, China
}

\begin{abstract}
-distance teaching has become one of the important approaches for people to acquire knowledge. However, due to time limit, it is very difficult for people to spare much time from work and life on distance teaching. Besides, there are numerous employees who have mastered some knowledge in their fields, so it is unnecessary to complete all courses of distance teaching. Thus, retrieval knowledge acquisition becomes very crucial. The author proposed a courseware teaching system with retrieval function which effectively solves courseware retrieval, based on multimedia information such as image, audit and video. The author applied this system in actual teaching of "Sports Psychology" course. This course gained favorable teaching effect, and improved students' learning efficiency and learning effect as well as their initiative and enthusiasm for acquiring knowledge.
\end{abstract}

Index Terms-courseware, teaching, information retrieval, Sports Psychology

\section{INTRODUCTION}

Sports Psychology is a branch of psychology which aims to study human psychological characteristics and laws during engaging in sports. Sports Psychology as an emerging subject in sports science, is closely related to Sports Science, Sport Sociology, Exercise Physiology, Sports Training Theory and Method as well as theories and methods of other sports. Moreover, it is an essential course of PE specialty [1]. This course mainly narrates the effects of cognition, emotion, will and individuality on physical exercise. It analyzes people's psychology in sports skill formation process, training process, competition process and guides athletes how to master good psychological skills and mentality. Stolz and Pill suggested the teaching of PE course including Sports Psychology should be combined with sports games [2]. This teaching experiment result shows that such teaching mode is welcomed by students.

With continuous development of network and multimedia information, distance teaching has become one of the important approaches for people to acquire knowledge. However, due to time limit, it is very difficult for people to spare much time from work and life on distance teaching. Besides, there are numerous employees who have mastered some knowledge in their fields, so it is unnecessary for them to complete all courses of distance teaching. Thus, retrieval knowledge acquisition becomes very crucial. Smeaton [3] designed a set of document retrieval system which achieves courseware retrieval, based on language processing framework. Mittal et al. [4] applied content classification representation to design a set of courseware retrieval method on the basis of ontology, and the courseware retrieval method can be used in distance teaching. Yuan et al. [5] designed Solar-based multimedia teaching courseware cloud retrieval system. This system achieved efficient and flexible courseware cache, online retrieval, duplication checking and highlight display functions and improved usability through index duplication. Yan et al. [6] designed ontology-based courseware resource retrieval system by combining ontology and Agent technology. It provided individualized courseware retrieval service, achieved courseware resource sharing, boosted courseware making efficiency and reduced teacher's pressure of courseware making. Existing researches solve the problem of massive courseware information retrieval to some extent. But they fail to fundamentally resolve fundamentally retrieval problem in distance teaching and especially fail to effectively settle courseware retrieval problem based on image, audio and video. The author put forward a courseware teaching system with retrieval function, applied it in actual teaching of "Sports Psychology" and gained favorable teaching effect.

\section{INFORMATION RETRIEVAL TECHNOLOGY}

\section{A. Basic concept of information retrieval}

The full name of Information Retrieval [7] is "Information Storage and Retrieval". Information retrieval refers to a process of organizing and storing of information according to certain method and finding out relevant information according to users' needs [7].

\section{B. Principle of information retrieval}

Information retrieval is divided into two parts: information storage and information retrieval. In information storage process, it is necessary to carry out information screening for information source, transform information and storage information into database in accordance with predefined unity concept. In information retrieval process, the system transforms retrieval request to retrieval language according to predefined unity concept, retrieve and feedback retrieval results.

\section{Text information retrieval}

Text information retrieval, also called natural language retrieval, refers to a technology of word matching, seeking in natural language directly through the computer without any indexing of literature. The earliest and most typical text retrieval is book index of a library. The books are indexed according to book's name, author, publishing house, publishing time and book number. Readers can seek the books they want according to the index. 


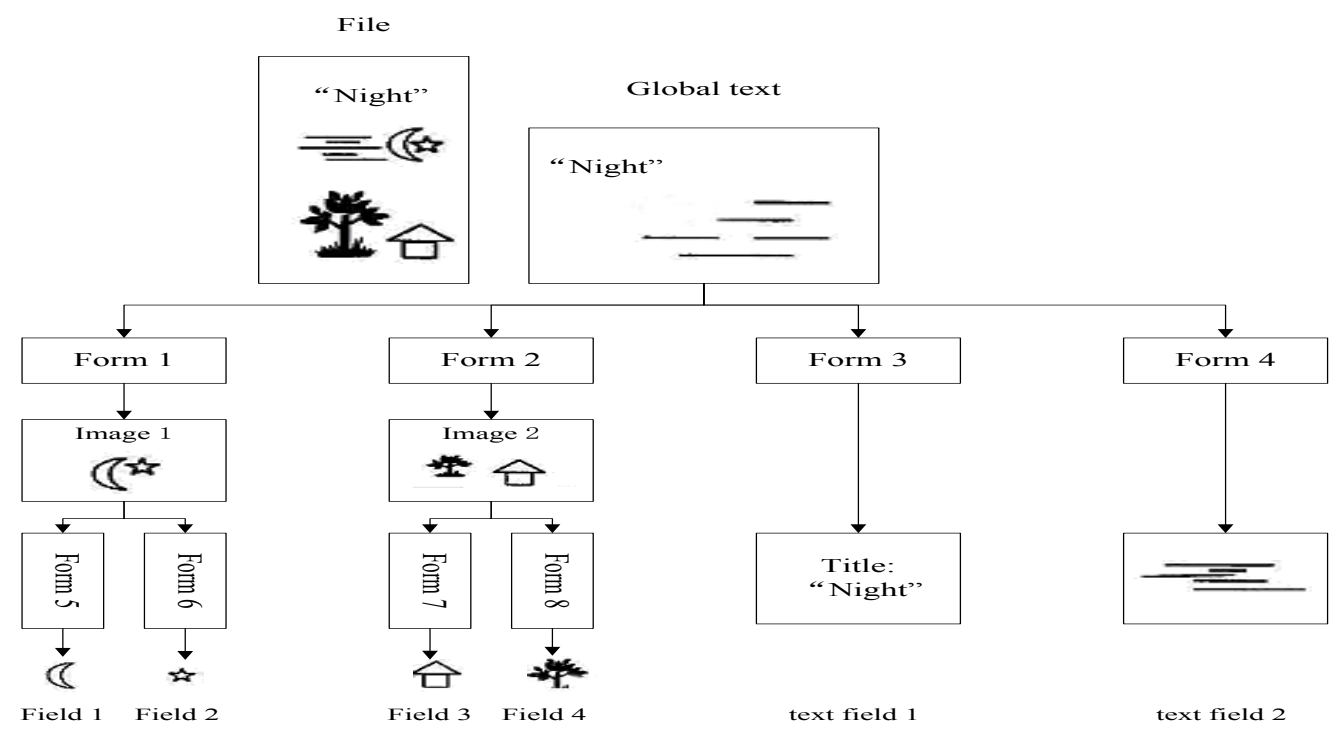

Figure 1. Example of multimedia information element subdivision

\section{Multimedia information retrieval}

In content-based multimedia information (such as image, speech and video) retrieval, the color, texture, shape, motion and other visual features as well as audio features are extracted to characterize semantics of multimedia content so as to realize query and management of multimedia data. Figure 1 shows an example of hierarchical storage of multimedia file. Multimedia file is divided into several multimedia element domains to achieve retrieval positioning.

\section{INFORMATION RETRIEVAL TECHNOLOGY}

The implementation of courseware teaching system with retrieval function depends on scientific information storage and retrieval process design under the help of audio/video information separation, speech text information conversion and information synchronization method.

\section{A. System process design}

In this experiment, the retrieval process of courseware teaching system with retrieval function can be divided into: courseware information storage process and courseware information retrieval process, as shown in Figure 2 and Figure 3.

In multimedia courseware information storage process, courseware information can be classified into three types (text, image and audio) according to different courseware information component elements. Text information may come from textbook, PPT courseware, note and blackboard writing etc.; image information may come from classroom teaching video and PPT courseware etc.; audio information may come from classroom teaching recording, music and classroom teaching video etc. The three types of information are stamped with timestamp according to time sequence of course teaching to make text image and audio information establish relevance with time. Then, the three types of information are segmented on the basis of teaching content, and segmented elements are connected with possible key words for retrieval for the sake of retrieval.

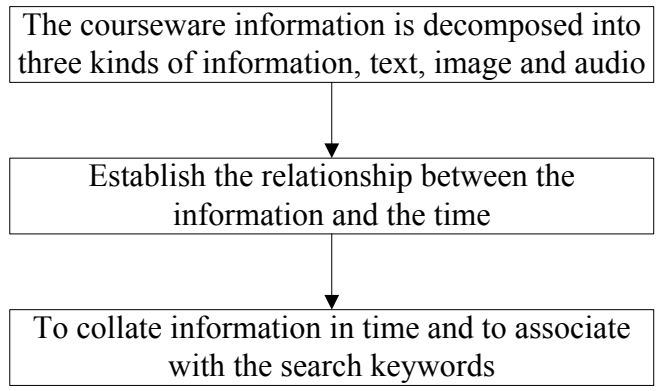

Figure 2. Schematic diagram of multimedia courseware information storage process

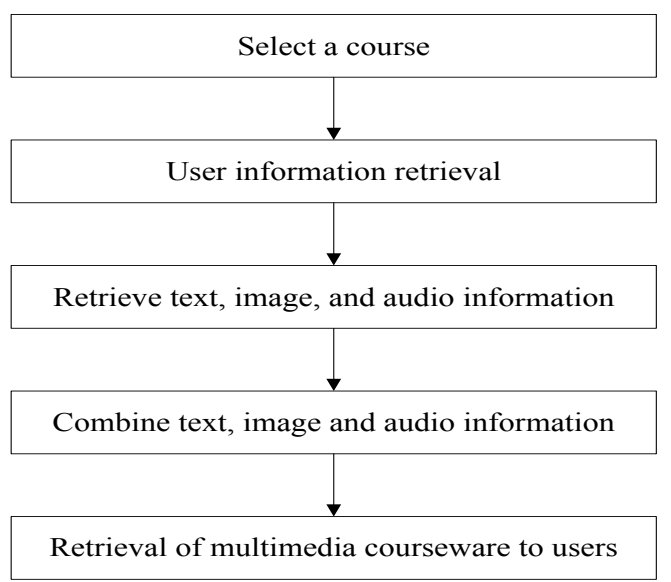

Figure 3. Schematic diagram of multimedia courseware information retrieval process

In multimedia courseware information retrieval process, users choose a course they are interested in, the system will acquire relevant information of the course and display it. Users further retrieve, and the system acquires courseware-related text, image and audio information according to the retrieval. It integrates the three types of information according to time relationship to form users' multimedia courseware information and present it to users. 


\section{B. Audio/video information separation method}

As previously mentioned, we will encounter the need of separation of audio information from the video in multimedia courseware information storage process.

Because of information technology progress, relevant techniques about extraction of audio signals from video file have become quite mature. Power Video Converter, Total Video Converter and other common software are good audio extraction tools, and they can easily extract audio information from video file [9].

\section{Speech text transformation method}

In courseware information storage process, speech recognition technology can be used to transform large quantities of speech signals to corresponding text information. Speech recognition technology is also called Automatic Speech Recognition (ASR). Its objective is to transform human speech to the input that the computer can be read, including code or character sequence. In this application, speech signal needs to be transformed to text character sequence. Office Word 2000 software of ViaVioce and Microsoft manufactured by IBM well supports speech text transformation function.

\section{Information synchronization method}

As network technology, communication technology and multimedia technology popularize rapidly, and computer operation speed, network bandwidth and data compression technique improve significantly, distance teaching application has higher and higher requirements for online information transmission quality.

In this paper, the author proposes timestamp-based method to achieve the goal of text, image and audio information synchronization. Firstly, text, image and audio information are marked with timestamp. Then, the three types of information are segmented according to information content. Finally, segmented three types of information elements are transmitted to client respectively and are integrated at the client according to the timestamp. This avoids possible non-synchronization problem in transmission process and achieves text, image and audio courseware information synchronization at client.

\section{E. System interface design}

In terms of page navigation, traditional distance course platform navigation style is followed. The list is applied to present corresponding online courses, as shown in Figure 4.

Course display page is divided into image information display zone, text information display zone, audio information control button and information retrieval zone, as shown in Figure 5. Users input retrieval conditions, and the retrieval results are presented in the form of list. When users select course segment in the retrieval result list, the text, image and audio information can be presented synchronously in corresponding zone.

\section{EXPERIMENTAL DESIGN OF SYSTEM IN "SPORTS PSYCHOLOGY" COURSE TEACHING}

To verify the effect of "courseware teaching system with retrieval function" in "Sports Psychology" distance teaching course, the author designed relevant experiments.

The author chose 334 undergraduates of eight teaching classes in 2014 PE specialty as the objects of study. They were divided into two groups at random, including experimental group (174 students) and control group (160 students). The baseline survey shows the differences of students in experimental group and control group in specialty cognition level and learning motivation have no statistical significance $(\mathrm{P}>0.05)$.

In the teaching process of "Sports Psychology" distance course, the students in experimental group adopted "courseware teaching system with retrieval functions" for study, while the students in control group applied "distance courseware teaching system" for study.

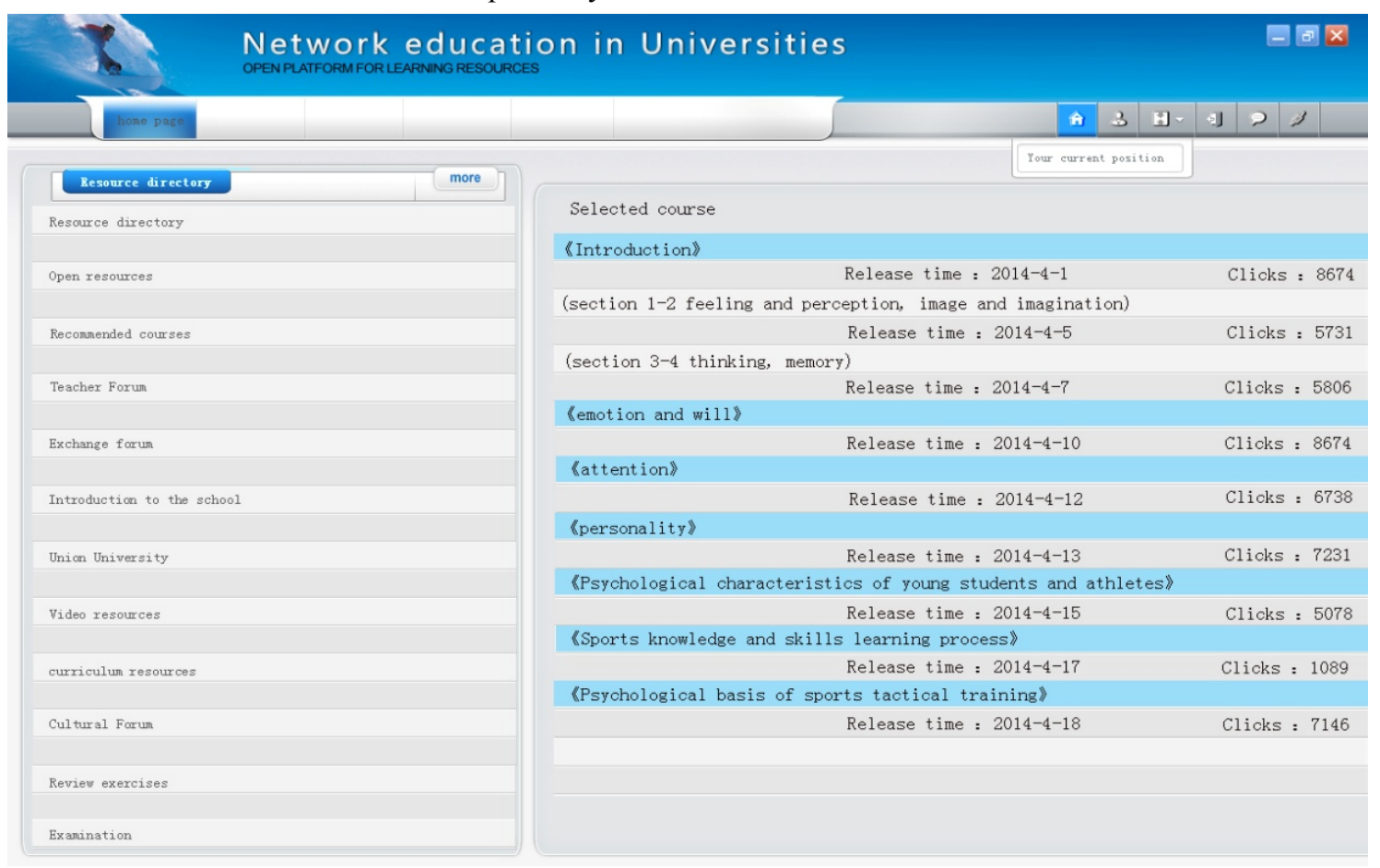

Figure 4. Screenshot of distance course list 


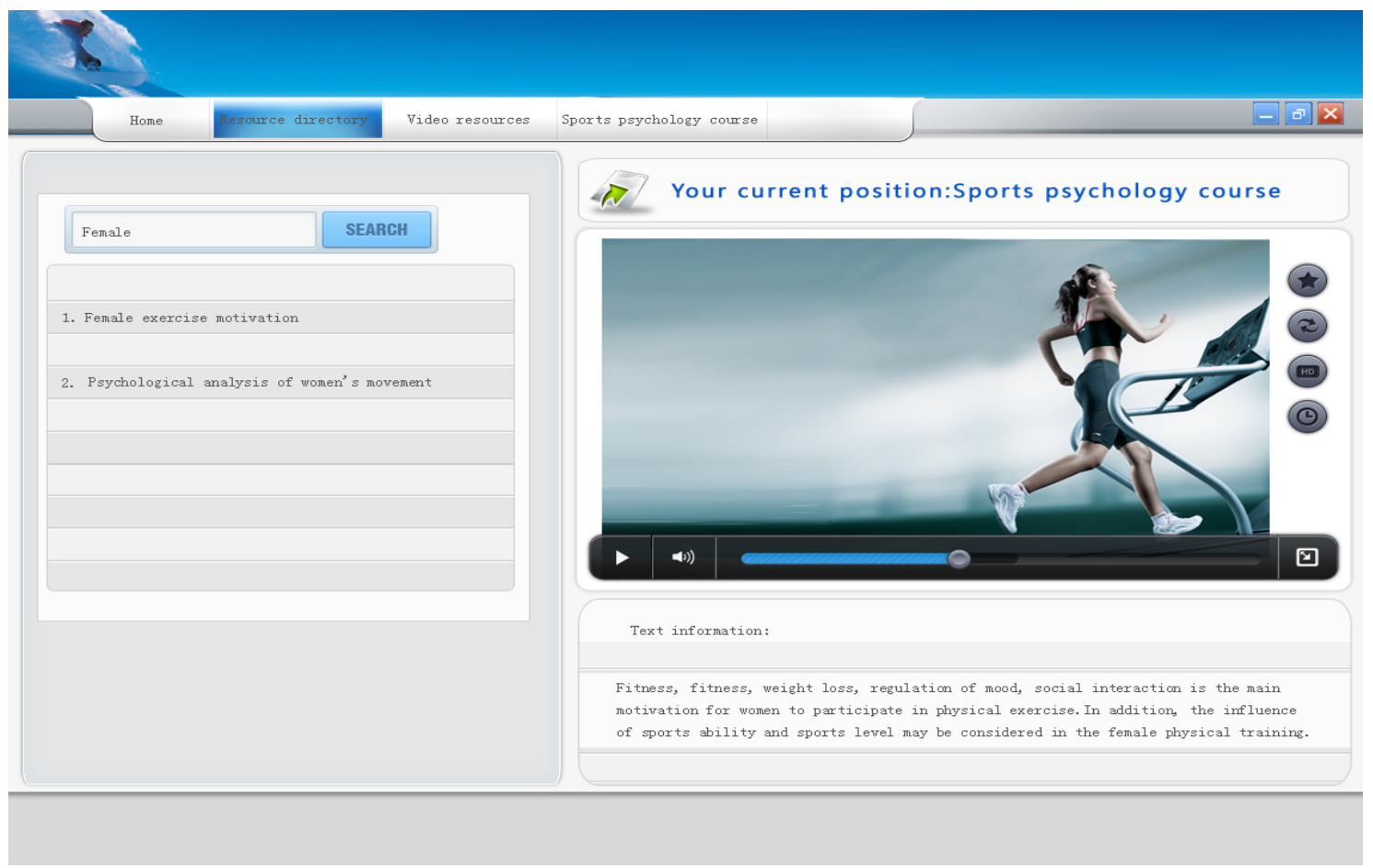

Figure 5. Screenshot of Sports Psychology course display

At the end of the semester, the same examination paper was used to test students in two groups, with full score of 100. In addition, the same set of questionnaire was used to survey learning motivation of students in two groups. This set of questionnaire was prepared by Tian Lan et al. in 2006 [10], including four dimensions: knowledge seeking interest, ability pursuit (internal motivation), reputation acquisition and altruism orientation (external motivation), with a total of 34 items. This questionnaire adopted Likert 5-score system. Higher score means higher learning motivation. Total Coronbach's $\alpha$ coefficient of the questionnaire was 0.935 . The students in both groups participated in questionnaire survey, and the recovery rate reached $100 \%$. The questionnaire survey was filled in on the site so as to offer guidance for filling and to guarantee $100 \%$ effective rate of questionnaire.

\section{EXPERIMENTAL RESULTS AND ANALYSIS}

\section{A. Data entry and statistical analysis}

Epidata 3.1 software was applied to type in students' test score and questionnaire in a parallel way. Then inspection was conducted to ensure no error. Then, SPSS 19.0 software was used for statistical analysis. Quantitative data were expressed with mean \pm standard deviation. Independent-sample $\mathrm{T}$ test was adopted for inter-group comparison, with inspection level $\alpha=0.05$

\section{B. Experimental results}

Statistical analysis of test scores of students in both groups is shown in Table 1. The difference of experimental group and control group in test scores has statistical significance $(\mathrm{t}=8.376, \mathrm{P}<0.001)$.

TABLE I.

TEST SCORE STATISTICS

\begin{tabular}{l|c|c|c|c}
\hline \multicolumn{1}{c|}{ Group } & Number & $\begin{array}{c}\text { Beverage } \\
\text { score }\end{array}$ & $\begin{array}{c}\text { Highest } \\
\text { score }\end{array}$ & $\begin{array}{c}\text { Lowest } \\
\text { score }\end{array}$ \\
\hline Experimental group & 174 & $90 \pm 7$ & 96 & 83 \\
\hline Control group & 160 & $84 \pm 6$ & 92 & 72 \\
\hline
\end{tabular}

Statistical results of learning motivation of students in both groups are shown in Table II. In the aspect of internal motivation, experimental group is larger than the control group in terms of total score, knowledge seeking interest and ability pursuit, and the difference has statistical significance $(\mathrm{P}<0.05)$. In the aspect of external motivation, although inter-group comparison has slight difference in total score, reputation acquisition and altruism orientation, the difference does not show statistical significance $(\mathrm{P}>$ $0.05)$.

TABLE II. COMPARISON OF LEARNING MOTIVATION SCORE $(X \pm \mathrm{S})$

\begin{tabular}{|c|c|c|c|c|c|c|c|}
\hline \multirow[b]{2}{*}{ Group } & \multirow{2}{*}{$\begin{array}{c}\text { Num- } \\
\text { ber }\end{array}$} & \multirow[b]{2}{*}{ Total score } & \multicolumn{2}{|c|}{ Internal motivation } & \multirow[b]{2}{*}{ Total score } & \multicolumn{2}{|c|}{ External motivation } \\
\hline & & & $\begin{array}{c}\text { Knowledge seeking } \\
\text { interest }\end{array}$ & Ability pursuit & & $\begin{array}{l}\text { Reputation } \\
\text { acquisition }\end{array}$ & $\begin{array}{c}\text { Altruism orienta- } \\
\text { tion }\end{array}$ \\
\hline Experimental group & 174 & $65.36 \pm 14.17$ & $37.36 \pm 9.09$ & $27.99 \pm 5.95$ & $49.16 \pm 10.56$ & $21.81 \pm 5.77$ & $27.34 \pm 5.74$ \\
\hline Control group & 160 & $61.99 \pm 14.84$ & $35.39 \pm 8.83$ & $26.59 \pm 6.19$ & $48.06 \pm 11.23$ & $21.78 \pm 5.87$ & $26.29 \pm 6.19$ \\
\hline t value & & 2.123 & 2.006 & 2.107 & 0.923 & 0.047 & 1.609 \\
\hline $\mathrm{P}$ & & 0.035 & 0.046 & 0.036 & 0.357 & 0.962 & 0.109 \\
\hline
\end{tabular}




\section{Result analysis}

With regard to academic performance, the score of students in experimental group is significantly higher than that in control group according to Table 1. This indicates the influence of courseware teaching system with retrieval function on students' academic performance is positive and significant. With the help of retrieval function, students may put limited time in knowledge points they fail to fully master and need not learn each knowledge point according to the sequence. Thus, they improve learning efficiency and learning effect through skipping over the contents that they are familiar with.

As for learning motivation, it can be seen from table II that, the scores of students in experimental group are higher than those in control group in terms of internal motivation, knowledge seeking interest and ability pursuit, and the difference presents statistical significance $(\mathrm{P}<$ 0.05). In the opinion of Brunner - a representative of cognitive psychology school, the best learning motivation is not external reward or competition, but learners' interest in the learning content. Retrieval function of the system can cultivate and mobilize students' interest in actively exploring unknown field, unlike passive cramming-based study under traditional teaching mode. Therefore, except boosting students' academic performance, the system improves students' initiative and enthusiasm for acquiring knowledge.

\section{CONCLUSIONS}

Among the students of Sports Psychology, retrievalbased knowledge acquisition is very important for them. For this reason, courseware teaching system with retrieval function owns excellent application prospect in Sports Psychology distance teaching and can meet up students' actual needs.

Courseware teaching system with retrieval function show significant positive promotion effects on academic performance and learning motivation in education field and especially Sports Psychology course, so it owns extensive application prospect.

\section{REFERENCES}

[1] Hein V., Ries F., Pires F., Caune A., Ekler J.H., Emeljanovas A., et al., "The relationship between teaching styles and motivation to teach among physical education teachers," Journal of sports science \& medicine, vol. 11, no. 1, pp. 123-130, March 2012.

[2] Stolz S., Pill S., "Teaching games and sport for understanding Exploring and reconsidering its relevance in physical education,"
European Physical Education Review, vol. 20, no. 1, pp. 36-71, February 2014. http://dx.doi.org/10.1177/1356336X13496001

[3] Smeaton A.F., Van Rijsbergen C.J., "The retrieval effects of query expansion on a feedback document retrieval system," The Computer Journal, vol. 26, no. 3, pp. 239-246, November 1983. http://dx.doi.org/10.1093/comjnl/26.3.239

[4] Mittal A., Krishnan P.V., Altman E., "Content classification and context-based retrieval system for e-learning," Journal of Educational Technology \& Society, vol. 9, no. 1, pp. 349-358 January 2006.

[5] Yuan X.P., Peng C., Sheng X.H., "Cloud retrieval system of Solrbased multimedia teaching courseware," Information Construction, no. 5, pp. 59, May 2015.

[6] Yan H., Li H., "Design of ontology-based courseware resource retrieval system," Computer Engineering and Design, vol. 27, no. 5, pp. 879-881, May 2006.

[7] Hsu D.F, Taksa I., "Comparing rank and score combination methods for data fusion in information retrieval," Information retrieval, vol. 8, no. 3, pp. 449-480, January 2005. http://dx.doi.org/10.1007/ s10791-005-6994-4

[8] Li H., "Learning to rank for information retrieval and natural language processing," Synthesis Lectures on Human Language Technologies, vol. 7, no. 3, pp. 1-121, October 2014. http://dx.doi.org/10.2200/S00607ED2V01Y201410HLT026

[9] Jung D.Y., Ji Y.H., Park S.H., Jung Y.C., Won C.Y., "Interleaved soft-switching boost converter for photovoltaic power-generation system," Power Electronics, IEEE Transactions on, vol. 26, no. 4, pp. 1137-1145, April 2011. http://dx.doi.org/10.1109/TPEL.2010. 2090948

[10] Tian L., Pan W.G., "preliminary preparation of undergraduate learning motivation questionnaire," Science of Social Psychology, vol. 21 , no. 6 , pp. 42-46, June 2006.

\section{AUTHORS}

Aili Qi (Corresponding author) is an Associate Professor in Guizhou University of Engineering Science, Bijie 551700, China. Her research interests include sports psychology and offline education (qiailili@yeah.net).

Yunsong Wang is a Lecturer in Guizhou Minzu University, Zunyi 550025, China. His research interests include physical education and offline education (wangyunsong22@yeah.net).

Chengchun Shen is an Associate Professor in Guizhou University of Engineering Science, Bijie 551700, China. His research interests include sports psychology and offline education (lifu2011@yeah.net).

This work was supported by College of Humanities and Social Sciences Research Projects of Guizhou Provincial Education Department [14QN064], College of Humanities and Social Sciences Research Projects of Guizhou Provincial Education Department [2015DXS29], Guizhou Provincial Education Science Plan Project [2013B123]. Submitted 10 December 2015. Published as resubmitted by the authors 25 February 2016. 